\section{Significance of New, Isolated T-wave Inversion in Multiple Electrocardiogram Leads with Regadenoson Injection in Patients with Normal Myocardial Perfusion Imaging: An Observational Report of 5 Consecutive Cases}

Robert T. Tung, M.D.

Department of Veterans Affairs Eastern Kansas Healthcare System, Topeka, KS

Received Oct. 17, 2018; Accepted for publication. June 4, 2019; Published online Aug. 21, 2019

\begin{abstract}
Introduction. The pharmacologic (regadenoson) stress myocardial perfusion imaging (MPI) is used widely in patients who cannot exercise for detecting coronary artery disease (CAD). The interpretation of these studies depends primarily on the imaging results because the sensitivity of electrocardiograms (ECG) in this setting is poor. Prior study showed that effects of regadenoson on ST-segment occurred infrequently and had low sensitivity for detecting CAD. The significance of T-wave inversion in multiple ECG leads without ST-segment depression with regadenoson injection in patients with normal MPI is described and reported.
\end{abstract}

Methods. ECGs were reviewed retrospectively in 64 patients who had regadenoson MPI and coronary angiography for evaluation of CAD from June 1, 2016 to August 31, 2018. Five cases were identified with new, isolated T-wave inversion in multiple ECG leads.

Results. All five cases had new and isolated T-wave inversion in multiple leads without ST segment depression with regadenoson injection and normal MPI. At coronary angiography, three of the five cases showed obstructive coronary artery disease who received coronary percutaneous intervention. One case had nonobstructive coronary artery disease and one had a normal coronary artery.

Conclusions. Despite nonspecific ST-T changes on baseline ECGs and normal MPI in all patients, three of five cases had obstructive CAD by coronary angiography. New, isolated T-wave inversion in multiple ECG leads with regadenoson injection were observed in our patients with normal MPI. These ECG findings may be associated with false negative MPI. Therefore, careful observation and scrutiny of all ECG changes, especially new, isolated T-wave inversion in multiple ECG leads during regadenoson MPI is advisable to identify potential obstructive CAD despite normal MPI findings.

\section{Kans J Med 2019;12(3):80-82.}

\section{INTRODUCTION}

The exercise electrocardiogram (ECG) is a well-validated procedure for establishing the diagnosis of obstructive coronary heart disease (CAD). ${ }^{1}$ One of the most identifiable ECG signs of myocardial ischemia during exercise testing is an ST-segment change. T-wave inversion can be seen on ECG in acute coronary syndrome or unstable angina and myocardial infarction., ${ }^{2,3}$ For patients who cannot exercise adequately, pharmacologic myocardial perfusion imaging (MPI) using adenosine, dipyridamole, and regadenoson is used widely as a diagnostic tool for detecting obstructive CAD, ${ }^{4,5}$ The interpretation

\section{KANSAS JOURNAL of MEDICINE}

of these studies depends primarily on the imaging results because the sensitivity of ECG in this setting is poor. ${ }^{5,6}$ Adenosine-induced STsegment depression is a highly specific marker for obstructive CAD. However, other ECG changes during pharmacologic stress testing have not been well described in predicting CAD. ${ }^{7}$ Specifically, the significance of T-wave inversion in multiple ECG leads without STsegment depression during regadenoson injection was described in a series of patients with normal MPI.

\section{METHODS}

ECGs were reviewed retrospectively in 64 consecutive patients who had regadenoson MPI and coronary angiography for evaluation of CAD from June 1, 2016 to August 31, 2018. Five cases were identified with new, isolated T-wave inversion in multiple ECG leads with regadenoson injection.

\section{RESULTS}

The clinical characteristics, ECG, and coronary angiographic findings of these five cases are summarized in Tables 1 and 2. Despite normal MPI in these patients, coronary angiography was performed because their clinical presentations were highly suggestive of significant CAD. The ECGs before and after regadenoson injection in cases one, two, and three are shown in Figure 1. At coronary angiography, three of the five cases showed obstructive coronary artery disease, three underwent percutaneous intervention, and case five had nonobstructive CAD as determined by fractional flow reserve (FFR) method. ${ }^{8}$

Table 1. Patient's characteristics and clinical presentation.

\begin{tabular}{|l|c|c|c|c|c|}
\hline Case Number & $\mathbf{1}$ & $\mathbf{2}$ & $\mathbf{3}$ & $\mathbf{4}$ & $\mathbf{5}$ \\
\hline Sex & Male & Male & Male & Male & Male \\
\hline Age (years) & 75 & 59 & 63 & 74 & 55 \\
\hline Known CAD & - & - & - & - & + \\
\hline Risk Factors & + & + & + & - & + \\
\hline Hypertension & - & - & + & + & + \\
\hline Diabetes & + & + & + & + & + \\
\hline Hyperlipidemia & - & + & + & - & + \\
\hline Smoking history & - & + & - & - & + \\
\hline Early family history of CAD & & & & & \\
\hline Clinical Presentations & + & - & + & + & + \\
\hline Typical angina & - & + & - & - & - \\
\hline Dyspnea
\end{tabular}


KANSAS JOURNAL of MEDICINE

T-WAVE INVERSION IN REGADENOSON MYOCARDIAL

PERFUSION IMAGING

continued.

Table 2. ECG and coronary angiographic findings.

\begin{tabular}{|c|c|c|c|c|c|c|c|}
\hline Case & Baseline ECG & \multicolumn{3}{|c|}{ ECG: Regadenoson - T-Wave Inversion } & Other Description & Coronary Angiography Findings & Treatment \\
\hline & & $\begin{array}{c}\text { Onset } \\
\text { (sec) }\end{array}$ & $\begin{array}{c}\text { Offset } \\
\text { (min) }\end{array}$ & Lead Location & & & \\
\hline 1 & $\begin{array}{c}\text { Flat T-V5-6, inversion } \\
\text { aVF }\end{array}$ & $<50$ & $2: 50$ & II, III, V3-6 & Mild Biphasic T in V3 & $\begin{array}{c}\text { 70\% mLAD, } 80 \% \text { Dl, } 80 \% \text { RI, } \\
80 \% \text { RPDA }\end{array}$ & $\begin{array}{l}\text { PCI to all } 4 \\
\text { lesions }\end{array}$ \\
\hline 2 & Flat $\mathrm{T}$ in V3-6 & 50 & $>4: 50$ & II, III, aVF, V3-6 & & Normal & None \\
\hline 3 & $\begin{array}{c}\text { Flat T in II, III, aVF, } \\
\text { V3-6 }\end{array}$ & 50 & $>4: 50$ & II, III, aVF, V3-6 & & $90 \%$ mLAD, $50 \%$ Dl & $\begin{array}{l}\text { PCI to LAD } \\
\text { and Dl }\end{array}$ \\
\hline 4 & $\begin{array}{c}\text { Flat T in II, III, aVF, } \\
\text { V4-6 }\end{array}$ & 60 & 9:50 & II, III, aVF, V3-6 & $\begin{array}{c}\text { Mild Biphasic T in } \\
\text { V3 - } 4\end{array}$ & $95 \% \mathrm{LAD}$ & PCI to LAD \\
\hline 5 & $\begin{array}{l}\text { Notched T V3-5, } \\
\text { inverted V2-3 }\end{array}$ & 50 & $2: 50$ & V4-6 & $\begin{array}{c}\text { Flattening T in II, III, } \\
\text { aVF }\end{array}$ & $40 \%$ LAD \& RI, (-) FFR ${ }^{*}$ & Medical \\
\hline
\end{tabular}

*FFR of 0.85 in LAD, 0.98 in RI; normal value: $<0.8$.

Abbreviations: Dl: first diagonal branch of left anterior descending artery; ECG: electrocardiography; FFR: fraction flow reserve; min: minutes; mLAD: mid left anterior descending artery; PCI: percutaneous coronary intervention; RI: ramus intermedius; RPDA: right posterior descending artery; sec: seconds

Case $1 \quad$ Case $2 \quad$ Case 3

Before

After

Figure 1. ECGs before and after regadenoson injection.

\section{DISCUSSION}

The electrophysiologic consequences of myocardial ischemia are responsible for the typical ST-T wave abnormalities seen on the ECG. ${ }^{9}$ The ST-segment coincides with the plateau or phase two of ventricular repolarization, and the T-wave reflects the time sequence of phase three repolarization. The action potentials become markedly altered during localized myocardial ischemia with exercise testing resulting in ST-T changes. There are multiple causes of T-wave inversion and they are well described in the literature. ${ }^{10}$ In patients with unstable angina, T-wave inversion in the precordial leads have been reported since 1982 as narrow, sharp, and symmetrical waves reflecting high grade stenosis of proximal LAD." The ST-segment depression and/ or elevation during pharmacologic stress MPI were associated with severe CAD or future cardiac event. ${ }^{12,13}$

Regadenoson is a selective A2a receptor agonist that causes coronary vasodilatation through the production of cyclic adenosine monophosphate, stimulation of potassium channels, and decreased intracellular calcium uptake. ${ }^{14}$ The effects of regadenoson on ST-segment was studied by Zahid et al. ${ }^{7}$ ST-segment depression was seen in $15.7 \%$ of patients, however, the sensitivity of the finding for predicting ischemia on the nuclear images was low $(7.0 \%)$, therefore, it was thought of little clinical value. The effects of regadenoson on T-wave has not been reported to our knowledge.
In all our cases, new, isolated T-wave inversion were observed in multiple ECG leads after regadenoson injection without ST-segment depression. All cases had nonspecific ST-T changes on their baseline ECGs and normal MPI. At coronary angiography, three of five had obstructive CAD. The exact mechanism for this diffuse, new T-wave inversion without ST-segment changes after regadenoson infusion is not known. It may represent transient but diffuse micro-vascular ischemia induced by regadenoson as the location of $\mathrm{T}$-wave changes on ECG are not corresponding to the anatomical location(s) of severe coronary artery stenosis detected by coronary angiography in cases three and four. Thus, the transient and diffuse micro-vascular ischemia after regadenoson injection might blunt its vasodilatory effects on epicardial coronaries leading to false negative results of MPI in those patients with severe CAD. Further studies are necessary to elucidate the exact mechanisms of these ECG changes with regadenoson injection.

In conclusion, our case series showed for the first time that new, isolated T-wave inversion in multiple ECG leads with regadenoson injection were observed in our patients with normal MPI. These ECG findings may be associated with false negative MPI as three of them had obstructive CAD, but future, larger studies are needed for definitive conclusions regarding these ECG findings. At this time, careful observation and scrutiny of all ECG changes, especially new, isolated T-wave inversion in multiple leads with regadenoson injection during pharmacological MPI is advisable to identify potential obstructive CAD despite normal MPI findings. 


\section{REFERENCES}

${ }^{1}$ Weiner DA, Ryan TJ, McCabe CH, et al. Exercise stress testing. Correlations among history of angina, ST-segment response and prevalence of coronary-artery disease in the Coronary Artery Surgery Study (CASS). N Engl J Med 1979; 301(5):230-235. PMID: 449990.

2 Haines DE, Raabe DS, Gundel WD, Wackers FJ. Anatomic and prognostic significance of new T-wave inversion in unstable angina. Am J Cardiol 1983; 52(1):14-18. PMID: 6602539.

3 Alpert JS, Thygesen K, Antman E, Bassand JP. Myocardial infarction redefined - A consensus document of The Joint European Society of Cardiology/American College of Cardiology Committee for the redefinition of myocardial infarction. J Am Coll Cardiol 2000; 36(3):959-969. PMID: 10987628.

${ }^{4}$ Iskandrian AS, Heo J, Nguyen T, et al. Assessment of coronary artery disease using single-photon emission computed tomography with thallium-201 during adenosine-induced coronary hyperemia. Am J Cardiol 1991; 67(15):1190-1194. PMID: 2035439.

${ }^{5}$ Coyne EP, Belvedere DA, Vande Streek PR, Weiland FL, Evans RB, Spaccavento LJ. Thallium-201 scintigraphy after intravenous infusion of adenosine compared with exercise thallium testing in the diagnosis of coronary artery disease. J Am Coll Cardiol 1991; 17(6):1289-1294. PMID: 2016445.

${ }^{6}$ Gupta NC, Esterbrooks DJ, Hilleman DE, Mohiuddin SM. Comparison of adenosine and exercise thallium-201 single-photon emission computed tomography (SPECT) myocardial perfusion imaging. The GE SPECT Multicenter Adenosine Study Group. J Am Coll Cardiol 1992; 19(2):248-257. PMID: 1732349.

7 Zahid M, Kapila A, Eagan CE, Yusko DA, Miller ED, Missenda CD. Prevalence and significance of electrocardiographic changes and side effect profile of regadenoson compared with adenosine during myocardial perfusion imaging. J Cardiovasc Dis Res 2013; 4(1):7-10. PMID: 24023463.

8 Di Diego JM, Antzelevitch C. Acute myocardial ischemia: Cellular mechanisms underlying ST segment elevation. J Electrocardiol 2014; 47(4):486-490. PMID: 24742586.

9 Tonino PA, De Bruyne B, Pijls NH, et al. Fractional flow reserve versus angiography for guiding percutaneous coronary intervention. N Engl J Med 2009;360(3):213-224. PMID: 19144937.

${ }^{10}$ Hanna EB, Glancy DL. ST-segment depression and T-wave inversion: Classification, differential diagnosis, and caveats. Cleve Clin J Med 2011; 78(6):404-414. PMID: 21632912.

${ }^{11}$ de Zwaan C, Bar FW, Wellens HJ. Characteristic electrocardiographic pattern indicating a critical stenosis high in left anterior descending coronary artery in patients admitted because of impending myocardial infarction. Am Heart J 1982; 103(4 Pt 2):730-736. PMID: 6121481.

${ }^{12}$ Hart CY, Miller TD, Hodge DO, Gibbons RJ. Specificity of the stress electrocardiogram during adenosine myocardial perfusion imaging in patients taking digoxin. Am Heart J 2000; 140(6):937-940. PMID: 11099998.

13 Marshall ES, Raichlen JS, Kim SM, et al. Prognostic significance of STsegment depression during adenosine perfusion imaging. Am Heart J 1995; 130(1):58-66. PMID: 7611124.

14 Jaroudi WA, Iskandrian AE. Regadenoson: A new myocardial stress agent. J Am Coll Cardiol 2009; 54(13):1123-1130. PMID: 19761931.

Keywords: electrocardiograph, regadenoson, coronary artery disease 